\title{
Estudo da morfologia e da dureza por microindentação Vickers do ferro fundido branco hipoeutético e hipereutético
}

\section{Study of morphology and toughness in microindention a hypoeutectic and hypereutectic cast iron Vickers}

\author{
1 Alessandro Oliveira de Souza \\ 1 Everson Cruz da Silva \\ 1 Frederico de Aquino Carneiro \\ 1 Joana Martins Jorge \\ 1 Rafael lacillo Soares \\ 2 Ricardo de Freitas Cabral ricardo.cabral@foa.org.br
}

1 Discente do Mestrado Profissional em Materiais, UniFOA.
2 Professor Doutor, Centro Universitário de Volta Redonda - UniFOA / Centro Universitário Geraldo di Biase - UGB.

\section{Resumo}

O Ferro Fundido Branco é muito utilizado em peças com necessidade de elevada resistência à abrasão. É utilizado na fabricação de equipamentos para a moagem de minérios, pás de escavadeiras e outros componentes similares. Este trabalho tem como objetivo principal a caracterização microestrutural e a análise da Microdureza Vickers do Ferro Fundido Branco Hipoeutético e Hipereutético. As amostras foram preparadas metalograficamente, conforme norma ASTM E 407. Foram utilizados os seguintes equipamentos para análise da estrutura do material: Microscópio Óptico (MO), Microscópio Metalográfico Invertido, Microscópio Eletrônico de Varredura (MEV), Microdurômetro e Durômetro. O Ferro Fundido Branco Hipereutético apresentou dureza de $547 \mathrm{HV}$. Também foi verificado na miscroscopia do Ferro Fundido Branco Hipoeutético, a presença das dendritas de perlita constituídas de ledeburita e, ao fundo, a cementita disposta na matriz do material.

\section{Palavras-chave}

Ferro Fundido Branco Hipereutético; Ferro Fundido Branco Hipoeutético; Microestrutura; Microdureza Vickers.

\begin{abstract}
White Cast Iron is widely used in parts requiring high abrasion resistance. It is used in the manufacture of ore grinding equipment, excavator blades and similar components. This work has as main objective the microstructural characterization and the analysis of the Vickers Microhardness of the Hypoeutectic and Hipereutético White Cast Iron. The following materials were used to analyze the structure of the material: Optical Microscope (MO), Inverted Metallographic Microscope, Scanning Electron Microscope (SEM), Microdurometer and Durometer. The Hipereutético White Cast Iron presented a hardness of 547HV. The presence of the perlite dendrites made of ledeburite and, at the bottom, the cementite disposed in the matrix of the material was also verified in the microscopy of the Hipoeutético White Cast Iron.
\end{abstract}

\section{Keywords}

White cast iron; white cast iron hypoeutectic; white cast iron hypereutectic; Microhardness Vickers; microstructure.

\section{Como você deve citar?}

CABRAL, Ricardo de Freitas et al. Estudo da morfologia e da dureza por microindentação vickers do ferro fundido branco hipoeutético e hipereutético. Cadernos UniFOA, Volta Redonda, n. 32, p. 7-14, dez. 2016. 


\section{INTRODUÇÃO}

Para o material desta pesquisa são dois os fatores preponderantes na determinação da estrutura do ferro fundido: composição química e velocidade de resfriamento (CHIAVERINI, 2002). A maior influência relacionada à composição química é dada pela presença do silício e do carbono, podendo conter outros elementos químicos. 0 carbono determina a quantidade de grafita que se pode formar e o silício é, essencialmente, o elemento grafitizante, favorecendo a decomposição do carboneto de ferro. Sua presença, independentemente do teor de carbono, pode fazer um ferro fundido tender para o cinzento ou para o branco (CHIAVERINI, 2002; POULACHON, 2002).

Quando os ferros fundidos com baixo teor de silício são resfriados rapidamente, a maioria do carbono se encontra na forma de cementita $\left(\mathrm{Fe}_{3} \mathrm{C}\right)$ no lugar de grafita. A superfície de fratura dessa liga apresenta uma aparência esbranquiçada. Como esse material possui elevada dureza e alta fragilidade, torna assim, a sua usinagem virtualmente impossível e, dessa forma, limita as aplicações que exigem uma superfície muito dura e resistente ao desgaste, sem um alto grau de ductilidade, como, por exemplo, cilindro de laminação. (CALLISTER, 2008; CHAVES, 2011; XAVIER, 2010).

Este trabalho teve como objetivo realizar a caracterização microestrutural do material, por meio da análise de micrografias e ensaios de microdureza Vickers e dureza Rockwell e comparar os resultados obtidos com informações encontradas em bibliografias e estudos sobre o Ferro Fundido Branco. Por meio desses resultados, objetiva-se avaliar as propriedades mecânicas e estruturais do material.

\section{MATERIAIS E MÉTODOS}

Foram utilizadas barras retangulares do Ferro Fundido Branco Hipoeutético e Ferro Fundido Branco Hipereutético, que foram cortadas no tamanho desejado, utilizando-se uma Cortadora Metalográfica Teclago CM40 com disco abrasivo. Em seguida, as amostras foram embutidas a quente, utilizando-se baquelite, em uma Embutidora Metalográfica Arotec PRE 30Mi, com aquecimento até atingir $180^{\circ} \mathrm{C} \mathrm{e}$ resfriamento até chegar a $40^{\circ} \mathrm{C}$, sob uma pressão de trabalho de $120 \mathrm{kgf} / \mathrm{cm}^{2}$.

Após o embutimento, as amostras foram identificadas com a utilização de um pirógrafo e submetidas ao processo de lixamento, de acordo com a norma ABNT NBR 13284, utilizando-se uma Politriz Lixadeira Metalográfica Arotec e lixas de carbeto de silício. As granulações das lixas foram de $220,400,600,1000,1200$ e a 1500 microns. Cada amostra foi rotacionada a $90^{\circ}$ em torno de si, por aproximadamente 2 min por lixamento, cuja finalidade final seria a de se conseguir ver a microestrutura final do corpo de prova. Em seguida, o corpo de prova foi levado até o Microscópio Óptico marca Opton, que possui uma lente ocular de 10x e lentes objetivas de 10x, 20x e 40x e verificou-se a adequação ao padrão esperado, ou seja, uma superfície isenta de arranhões.

Após o lixamento e análise da superfície, foi realizado o polimento, utilizando-se uma Politriz com um feltro apropriado e alumina com diferentes granulações ( $1 \mu \mathrm{m} ; 0,3 \mu \mathrm{m}$ e $0,05 \mu \mathrm{m})$, a fim de se obter uma superfície espelhada, ideal para realizar a última etapa do procedimento, o ataque químico. 0 reagente utilizado para atacar quimicamente a amostra foi o Nital $3 \%$. Foi imersa a amostra durante $3 \mathrm{~s} \mathrm{em}$ um recipiente, contendo o reagente químico, para revelação das microestruturas típica do Ferro Fundido Branco Hipoeutética e do Hipereutética.

Após o ataque químico, as amostras foram lavadas e, em seguida, secas, a fim de isentá-las de qualquer impureza que pudesse dificultar a visualização da superfície atacada. Utilizou-se o Microscópio 
Metalográfico Invertido da marca Opton e modelo TNM-07T-PL e um Microcomputador com o software Scope Photo 3.0, para realizar a microscopia ótica nas ampliações desejadas.

Em seguida, foi realizada a Microdureza Vickers nas amostras, pelo uso de um Microdurômetro Time DHV-1000, com um indentador de diamante Vickers, que tem a forma de uma pirâmide de base quadrada com ângulo de $136^{\circ}$ entre as faces, e uma objetiva de $40 \mathrm{X}$, para realizar 10 indentações, durante $15 \mathrm{~s}$ em cada procedimento. Foi obedecida a distância de $1 \mathrm{~mm}$ de uma impressão a outra, utilizandose uma carga de $500 \mathrm{gf}$. Nesse ensaio, mediram-se as diagonais de indentação e obtendo-se a medida direta em HV no equipamento. $\mathrm{O}$ valor da dureza é dado em função da área impressa pela indentação que tem o formato de uma pirâmide invertida de diamante, cuja carga aplicada é em kgf, dividida pela média ao quadrado das diagonais de indentação em $\mathrm{mm}^{2}$, de acordo com a Eq. 1:

$$
H V=1,854 \frac{F}{d^{2}}
$$

onde:

$\mathrm{F}=$ é a carga em $\mathrm{kgf} ;$

$d$ = é a media aritmética das duas diagonais, $d_{1}$ e $d_{2}$ em mm;

$\mathrm{HV}=$ é a dureza Vickers.

Por outro lado, no ensaio de dureza, foi utilizado um Durômetro Pantec, modelo RANS-RS, onde se pode verificar a Dureza Rockwell Normal, Rockwell Superficial e Brinell. Para o experimento em específico, foi utilizada a Dureza Rockwell Normal. Para o início de utilização do Durômetro, se faz necessária a inserção de um contrapeso com a carga correspondente à análise a ser feita e também a execução de uma pré-carga de $10 \mathrm{~kg}$ de massa para apoiar o corpo de prova. 0 durômetro consiste de um penetrador de diamante com $120^{\circ}$ de conicidade com $150 \mathrm{kgf}$ de carga.

As análises por MEV foram realizadas em um equipamento da marca Hitachi modelo TM3000, para obtenção das imagens com ampliações maiores e mais detalhadas dos materiais. Para iniciar o processo, foi retirado o vácuo do compartimento do equipamento. Como o baquelite não é condutor, foi necessário colocar uma fita de cobre para promover a condutividade, pois as imagens são geradas pelos feixes de elétrons com intensidade de $5 \mathrm{kV}$ a $15 \mathrm{kV}$.

\section{RESULTADOS E DISCUSSÕES}

A Figura 1 (a) e (b), nos aumentos de 200 e 400X, respectivamente, apresentam as imagens por microscopia óptica de uma amostra do Ferro Fundido Branco Hipoeutético, no seu estado bruto de fusão, onde é possível observar as dendritas de perlita, áreas pontilhadas constituídas de ledeburita e as áreas brancas constituídas de cementita (CHIAVERINI, 2002; CHAVES, 2011; XAVIER, 2010). 
Figura 1 - Imagens da Microscopia Óptica do Ferro Fundido Branco Hipoeutético

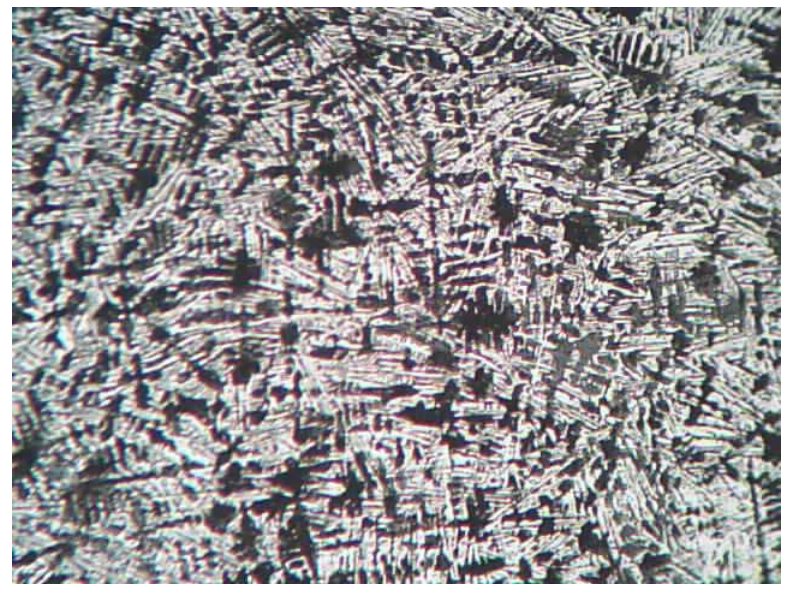

(a) ampliação de 200x;

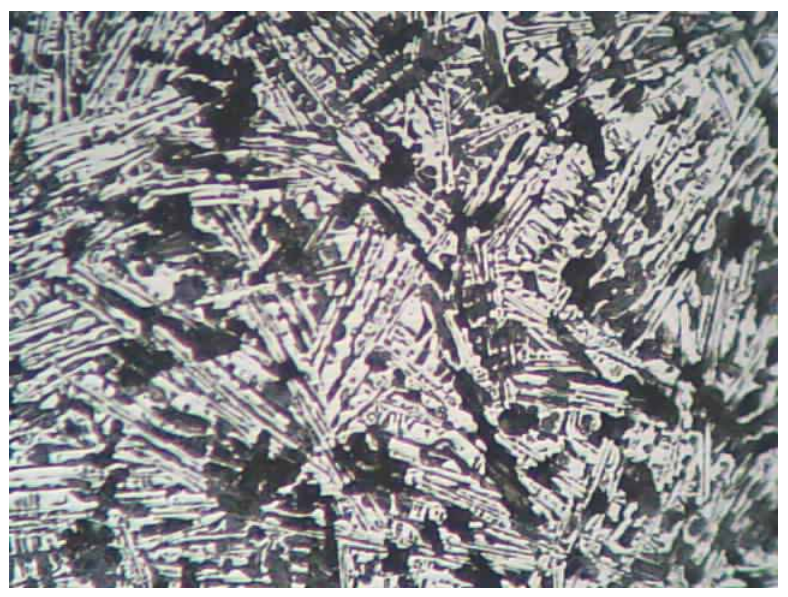

(b) ampliação de 400x.

Fonte: dos autores.

A Figura 2 (a) e (b), nos aumentos de 200 e 400X, respectivamente, apresentam as imagens por microscopia óptica de uma amostra do Ferro Fundido Branco Hipereutético, no seu estado bruto de fusão, onde é possível observar os longos cristais de cementita sobre um fundo de ledeburita (CHIAVERINI, 2002; CHAVES, 2011; XAVIER, 2010).

Figura 2 - Imagens da Microscopia Óptica do Ferro Fundido Branco Hipereutético

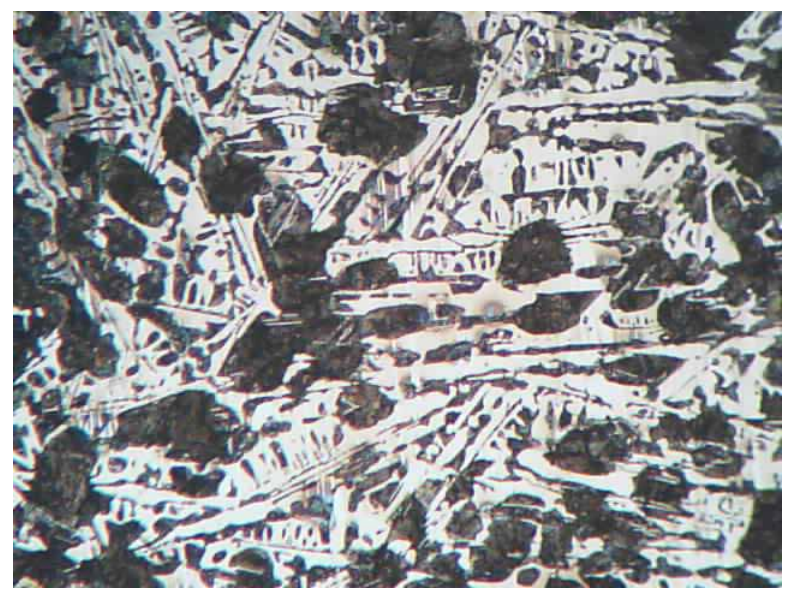

(a) ampliação de 200x;

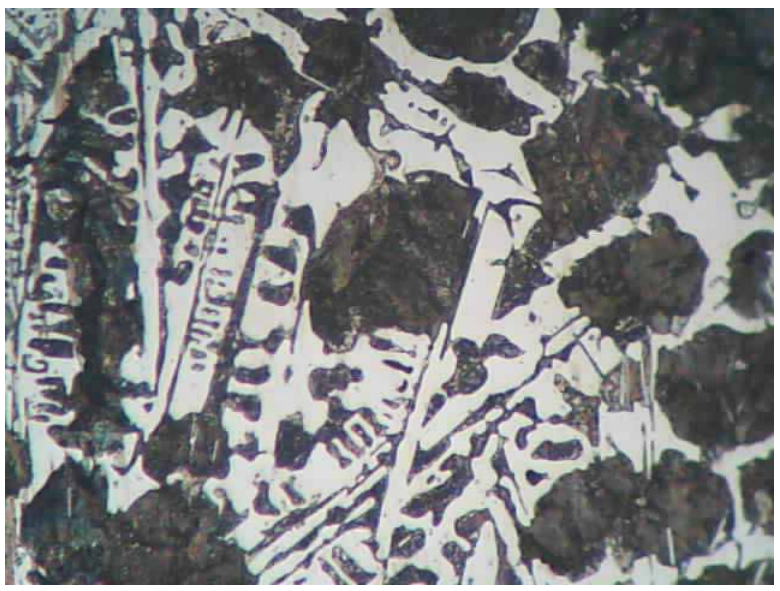

(b) ampliação de 400x.

Fonte: dos autores.

A microestrutura das Figuras 3 (a) e (b) ilustram as imagens por MEV, mostrando o aspecto micrográfico de um Ferro Fundido Branco Hipoeutético, nos aumentos de 2000 e 3000 X. Pela análise dessas imagens, foi possível observar nitidamente as dendritas de perlita constituídas de ledeburita e, ao fundo, a cementita disposta na matriz do material (MARANHÃO, 2006; BROEK, 2009), o que é comprovada com as imagens obtidas nas análises de microscopia óptica (Figuras 1 (a) e (b)). 
Figura 3 - Imagens por MEV do Ferro Fundido Branco Hipoeutético

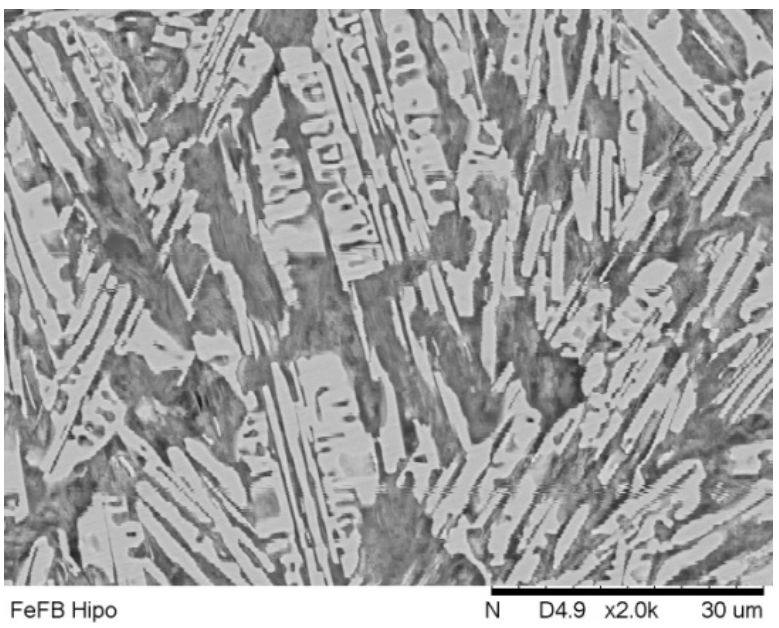

(a) ampliação de $2000 x$

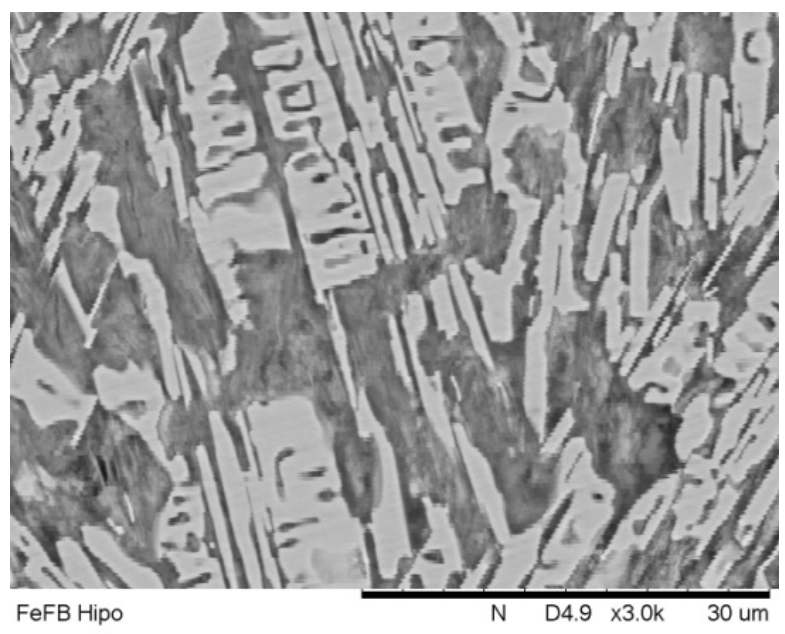

(b) ampliação de 3000x

Fonte: dos autores.

A microestrutura das Figuras 4 (a) e (b) ilustram as imagens por MEV, mostrando o aspecto micrográfico de um Ferro Fundido Branco Hipereutético, nos aumentos de 2000 e 3000 X. Pela análise dessas imagens, foi possível observar nitidamente os longos cristais de cementita e o fundo de ledeburita disposto na matriz do material (MARANHÃO, 2006; BRETAS, 2009), o que é comprovada com as imagens obtidas nas análises de microscopia óptica (Figuras 2 (a) e (b)).

Figura 4 - Imagens por MEV do Ferro Fundido Branco Hipereutético

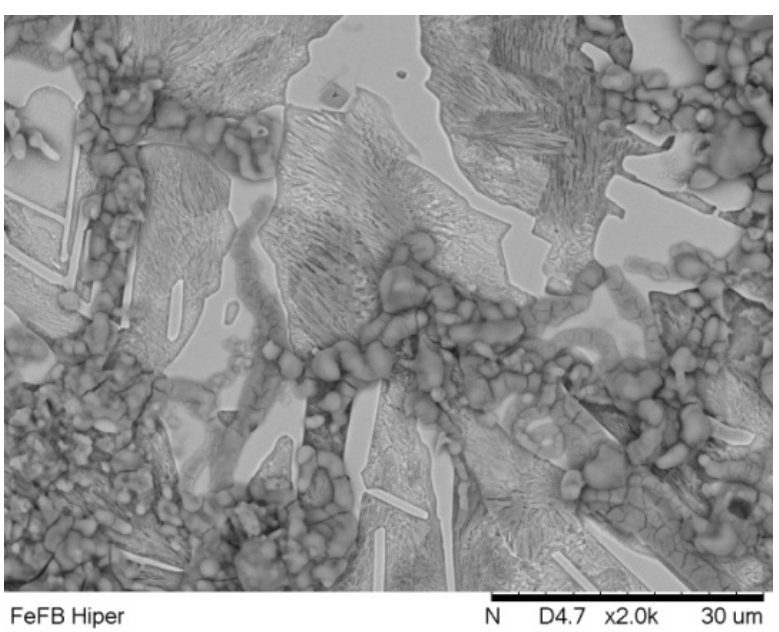

(a) ampliação de 2000x

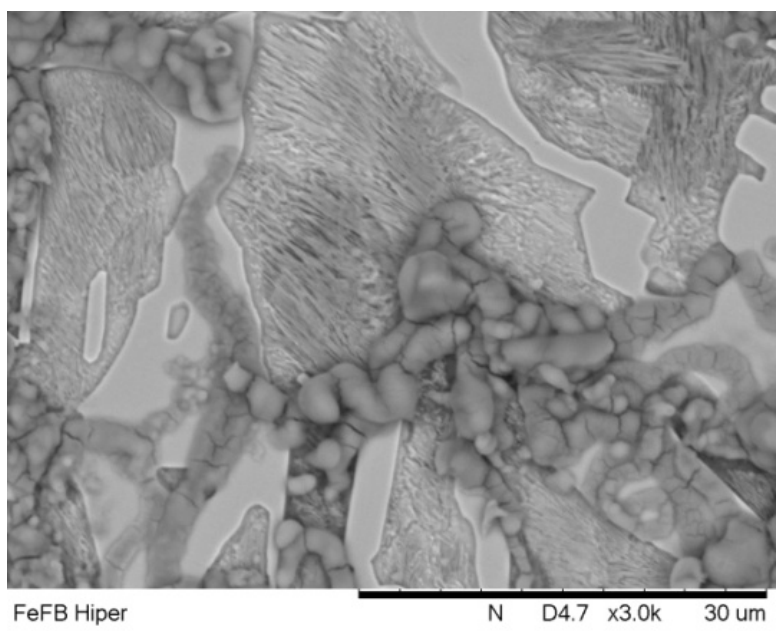

(b) ampliação de 3000x

Fonte: dos autores.

O Gráfico 1 mostra o comparativo da Dureza Vickers entre as duas amostras, onde nota-se claramente uma maior dureza da amostra de Ferro Fundido Branco Hipereutético, em relação à amostra de Ferro Fundido Branco Hipoeutético (GUESSER, 2009). 
Gráfico 1 - Comparativo da Dureza Vickers do

Ferro Fundido Branco Hipereutético e Hipoeutético, sob carga de 500 gf

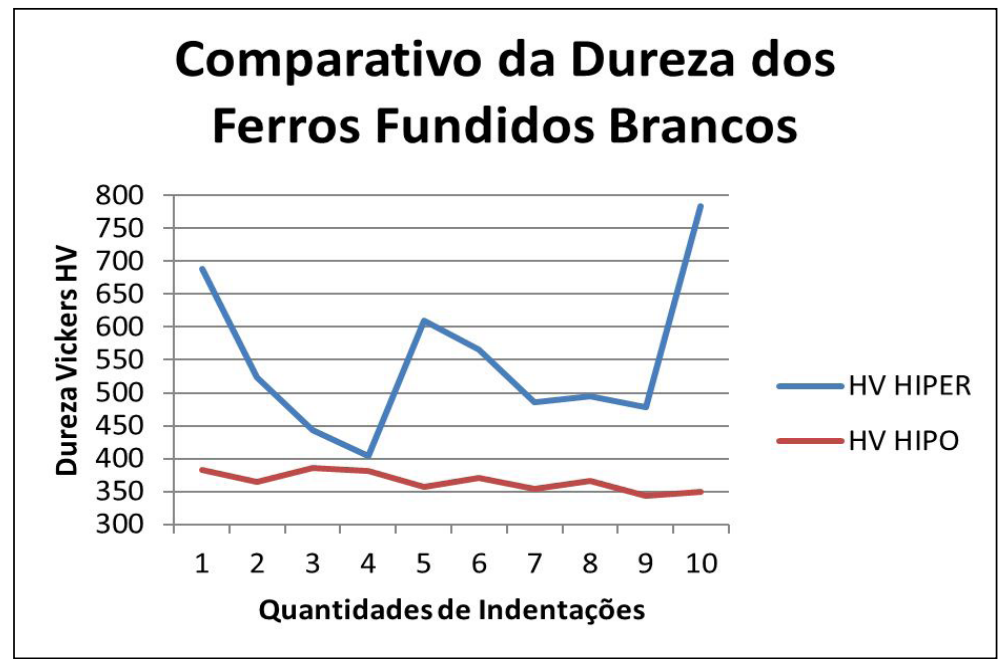

Fonte: dos autores.

Já no gráfico 2, que mostra o comparativo dos ensaios de Dureza Rockwell entre as duas amostras, os valores obtidos não correspondem ao esperado, pois evidenciam uma maior dureza da amostra de Ferro Fundido Branco Hipoeutético, em relação à amostra de Ferro Fundido Branco Hipereutético. Possivelmente, isso ocorreu devido à Dureza Rockwell abranger uma área muito maior durante a indentação, em relação aos demais ensaios, podendo ter atingido alguma inclusão metálica desconhecida (MARANHÃO, 2006).

Gráfico 2 - Comparativo da Dureza Vickers do Ferro Fundido Branco Hipereutético e Hipoeutético, sob carga de 500 gf

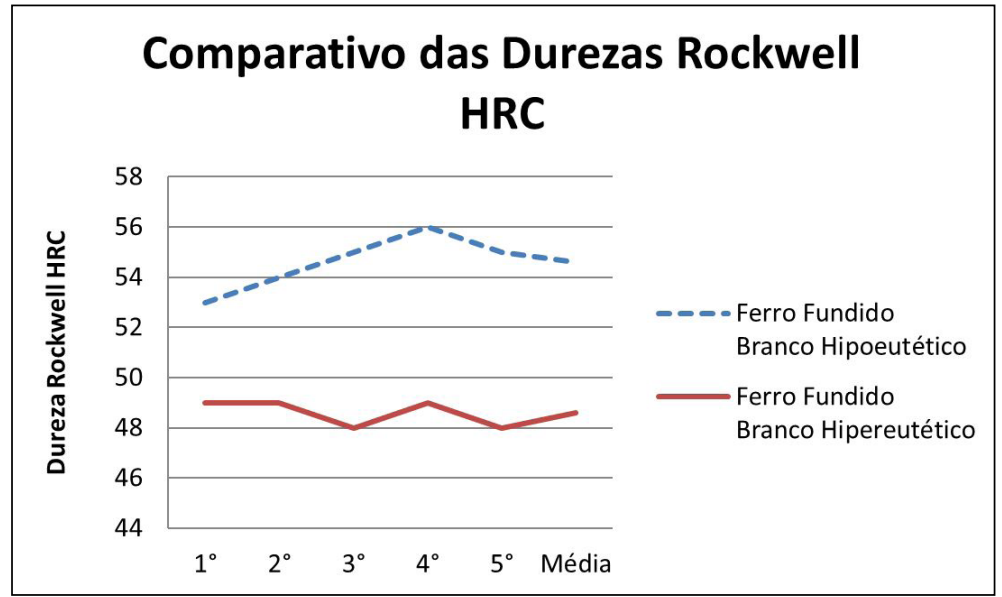

Fonte: dos autores. 


\section{CONCLUSÕES}

A morfologia dos materiais estudados apresentou-se de forma coerente, bem homogênea e com ausência de defeitos superficiais.

A amostra de Ferro Fundido Branco Hipoeutético apresentou uma menor microdureza da ordem de $365 \mathrm{HV}$, em relação ao Ferro Fundido Branco Hipereutético, que apresentou 547HV. Sendo que, nas extremidades onde ocorreram os cortes, houve um aumento significativo da microdureza.

Para os resultados de Dureza Rockwell, o Ferro Fundido Branco Hipoeutético obteve uma Dureza, em média, 12\% maior que o do Ferro Fundido Branco Hipereutético.

O ensaio comprova a influência da formação da cementita na dureza do material, que tem ainda como característica a resistência ao desgaste.

\section{REFERÊNCIAS}

ASSOCIAÇÃO BRASILEIRA DE NORMAS TÉCNICAS. NBR 13284: Preparação de corpos-de-prova para análise metalográfica: Procedimento. Rio de Janeiro, 1995.

BRETAS, Rodrigo Avancini. Análise da usinagem de roscas por interpolação helicoidal no ferro fundido vermicular. 2009. Dissertação (Mestrado em Materiais) - Instituto Superior Tupy, Joenville, 2009.

BROEK, D. Elementary Engineering Fracture Mechanics, Martinus Nijhoff, The Nerthlands. 612p, 2002.

CALLISTER Jr, W. D. Ciência e engenharia dos materiais: uma introdução. 7. ed. Rio de Janeiro: LTC, 2008.

CHAVES, V. H.; TAVARES, J. M.; CORTEZ, P. C. UMA ABORDAGEM COMPUTACIONAL PARA SEGMENTAÇÃO DAS MICROESTRUTURAS DO FERRO FUNDIDO BRANCO HIPOEUTÉTICO BASEADO EM MORFOLOGIA MATEMÁTICA. VHC Albuquerque, JMRS Tavares, PC Cortez (Eds), p. 1-8, 2011.

CHIAVERINI, V. Aços e ferros fundidos. 7. ed. São Paulo: Associação Brasileira de Metalurgia e Materiais: ATM, 2002.

CIÊNCIA DOS MATERIAIS (Brasil). Disponível em: <http://www.cienciadosmateriais.org/index. php?acao=exibir\&cap=13\&top=242/>. Acesso em: 11 nov. 2015.

GUESSER, L. W. Propriedades Mecânicas dos ferros fundidos. São Paulo: Editora Blucher, 2009. 336p.

POULACHON, G. ET. AL.. Sulphide inclusion effects on tool-wear in high productivity milling of tool steels. Wear, v. 253, n. 3-4, p.339-356, 2002.

MARANHÃO, O. Aspersão térmica de ferro fundido branco multicomponente. 2006. Tese (Doutorado em Materiais) - USP, Universidade de São Paulo, São Paulo, 2006.

VIDAL, D. F. Análise de estrutura e propriedades mecânicas de um ferro fundido nodular em processo de fundição produzido pela técnica de imersão de sino. 2013. Dissertação (Mestrado em materiais) UENF, Universidade Estadual do Norte Fluminense Darcy Ribeiro, Rio de Janeiro, 2013. 
XAVIER, Renato Rufino. Efeito do tratamento térmico nas propriedades mecânicas e resistência ao desgaste de um ferro fundido branco multicomponente, Estado de São Paulo, Brasil. 2010. Dissertação (Mestrado em Engenharia Mecânica) - FEG, Faculdade de Engenharia de Guaratinguetá, São Paulo, 2010. 